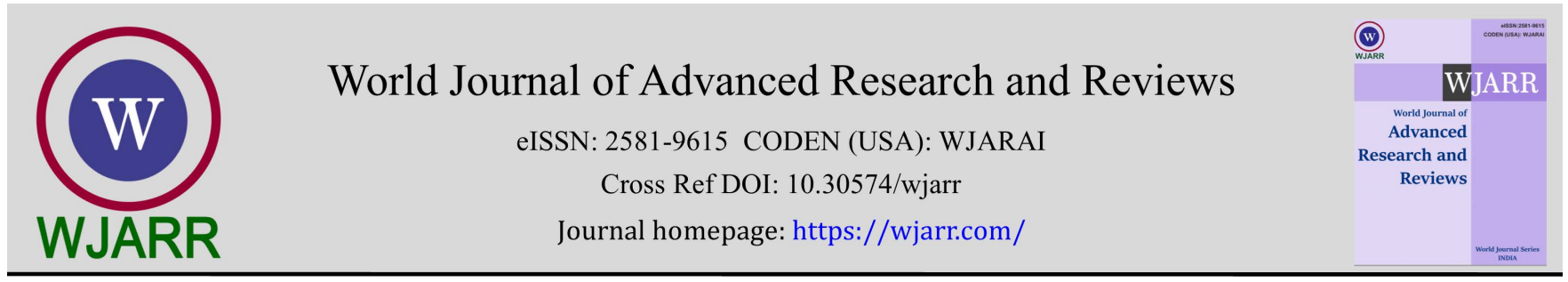

(REVIEW ARTICLE)

Check for updates

\title{
Addiction withdrawal syndrome: Needs medications, education, counselling \& support
}

\author{
Tapan Kumar Mahato $1{ }^{*}$, Sunil Kumar Ojha ${ }^{2}$, Vishwakarma Singh ${ }^{3}$ and Surendra Pratap Singh Parihar 4 \\ ${ }^{1}$ Department of Pharmaceutical Analysis, B.Pharmacy College, At Rampura, PO Kakanpur, Taluka Godhra, District \\ Panchmahal, Gujarat, India. \\ 2 Department of Pharmaceutics, B.Pharmacy College, At Rampura, PO Kakanpur, Taluka Godhra, District Panchmahal, \\ Gujarat, India. \\ ${ }^{3}$ Department of Pharmacology, B.Pharmacy College, At Rampura, PO Kakanpur, Taluka Godhra, District Panchmahal, \\ Gujarat, India. \\ ${ }^{4}$ Department of Pharmaceutics, Institute of Pharmacy, PK University, At Thanara (Karera), District Shivpuri, Madhya \\ Pradesh, India.
}

World Journal of Advanced Research and Reviews, 2021, 12(02), 143-150

Publication history: Received on 30 September 2021; revised on 05 November 2021; accepted on 07 November 2021

Article DOI: https://doi.org/10.30574/wjarr.2021.12.2.0573

\begin{abstract}
Addiction is a feel good or euphoria like condition which is commonly associated with drug abuse (opioid \& non-opioid), alcohol and nicotine intake. There are many reasons behind a man gets addicted to these substances such as recreation purpose, drugs used for long time for treatment of any disorder and gets addicted, unemployment, stress, emotions, professional pressure and social status. It provides enjoyable feelings which results in creating a strong urge to use the substances again and again. These drugs can cause physical dependence or psychological dependence or both. Over time, drug tolerance is produced which means to get the same effect more quantity of the drug is needed. These substances are very harmful physically, mentally, financially and socially too. If someone suddenly terminates using these substances after heavy or long term use, the body needs time to recover and number of withdrawal symptoms arises. These withdrawal symptoms can't be treated by medications only but it needs counselling and support as well. This article reviews i. the drug abuse (opioid \& non-opioid), alcohol and nicotine addictions with their withdrawal symptoms and medications used to treat these symptoms ii. Rehabilitation centers running and other steps taken by Government of India to aware people especially the youths of the country about the harmful effects of these substances.
\end{abstract}

Keywords: Drug abuse; Addiction; Addiction withdrawal; Withdrawal symptoms; Addiction withdrawal syndrome; Addiction withdrawal symptoms

\section{Introduction}

\subsection{Addiction, withdrawal \& withdrawal symptoms [1]}

\subsubsection{Addiction}

Addiction or dependence is the condition in which a person finds it hard to stop doing something that makes him/her feel good. It can develop physical addiction (withdrawal symptoms appears if the person stops the addictive substance like pain and shivering) or psychological addiction (occurs when a person believes that he/she need the addictive substance to function, without that they can't work) or both. Addiction is commonly associated with opioid drug abuse

${ }^{*}$ Corresponding author: Tapan Kumar Mahato

Department of Pharmaceutical Analysis, B.Pharmacy College, At Rampura, PO Kakanpur, Taluka Godhra, District Panchmahal, Gujarat, India.

Copyright (@ 2021 Author(s) retain the copyright of this article. This article is published under the terms of the Creative Commons Attribution Liscense 4.0. 
(illicit \& prescription), alcohol and nicotine. In simple words we can say that addicted person can't have control on its use and they may become dependent to run the daily life. There are many reasons behind a man gets addicted to these like for recreation, addiction arises due to medications used for prolonged period for treatment of any disorder, unemployment, stress, emotions, professional pressure and social status.

\subsubsection{Withdrawal}

Withdrawal is the process of reduced intake or giving up addictive substances such as opioids, alcohol or nicotine.

\subsubsection{Withdrawal symptoms}

When a addicted person stops using above substances physical, mental or both problems arises. These problems are called withdrawal symptoms. Withdrawal symptoms depends on type of addictive substance and how long it was used, age, physical and psychological characteristics and withdrawal process used. These symptoms vary from person to person which may be mild to severe. Common withdrawal symptoms includes insomnia, irritability, changing mood, depression, anxiety, aches and pains, cravings, fatigue, hallucinations, nausea, goose bumps and runny nose. Severe withdrawal symptoms may include paranoia (state of mind in which a person believes that others are trying to harm, cheat or exploit), confusion, tremors and feeling of illness. In some conditions, people become unpredictable and violent. Symptoms can lasts for a few days, week or some weeks.

\section{Opioid addiction \& withdrawal symptoms $[2,3,4,5,6,7]$}

Opioid drugs are big source of drug abuse as they can assist with mental relaxation and pain relief and can produce a sense of euphoria. Abuse of opioid drugs can be categorized into illicit drugs and prescription drugs. Illicit means those drugs whose transport, sale and use are totally prohibited. On the other hand, prescription drugs are those which are used for treatment of disorders and over the time the patient gets addicted to the medications. Examples of common opioids include codeine, fentanyl, hydrocodone, hydromorphone, morphine, oxycodone, oxymorphone, Heroin, Methadone, Meperidine and oxycontin.

\subsection{Illicit opioid drugs}

Some people become addicted to illicit recreational drugs such as heroin and marijuana. Heroin, an opioid drug made from morphine, a natural substance extracted from the seed pod of various opium poppy plants. It is injected, smoked or snorted. Marijuana (Cannabis)is made from the hemp plant, Cannabis sativa. The main psychoactive (mind-altering) chemical in marijuana is delta-9-tetrahydrocannabinol (THC).

\subsubsection{Common withdrawal Symptoms of heroin and marijuana addiction}

Major symptoms which arise after withdrawal are irritability, trouble sleeping, decreased appetite, anxiety, restlessness, muscle and bone pain, diarrhoea, vomiting and sudden shivery cold feeling with goose bumps.

\subsection{Prescription opioid drugs}

Opioids are a class of powerful prescription medicines that are used to manage pain when other treatments and medicines cannot be able to provide enough relief in pain. They have serious risks including abuse, addiction, overdose and death. When prescription drugs are taken without prescription for an unintended purpose, instead of becoming beneficial, it becomes dangerous, addictive and even deadly. These drugs can cause physical dependence. This means that a person relies on the drug to prevent withdrawal symptoms. Over time, more of the drug is needed for the same effect. This is called drug tolerance. When the person stops taking the drugs, the body needs time to recover. This causes withdrawal symptoms. Opioid withdrawal syndrome may be life-threatening. Commonly abused prescription drugs of this category are:

\subsubsection{Oxycodone}

Oxycodone is an opioid medication available singly or in combination with acetaminophen. It changes how your central nervous system (CNS) responds to pain.

\subsubsection{Codeine}

Codeine is typically prescribed to treat mild to moderate pain. It's also combined with other medications to treat cold and flu symptoms. For example, it is commonly found in prescription-strength cough syrup. When consumed in high quantities, codeine-based cough syrup has a sedative effect. It can also cause altered levels of consciousness. 


\subsubsection{Fentanyl}

Fentanyl is a synthetic opioid. It's prescribed for acute and chronic pain, typically in people with cancer. It is 50 to 100 times stronger than morphine. It creates feelings of euphoria and relaxation. Fentanyl misuse may lead to hallucinations and bad dreams.

\subsubsection{Meperidine}

Meperidine is a synthetic opioid. It's typically used to treat moderate to severe pain. Like other opioids, it produces feelings of euphoria.

Other drugs arehydrocodone, oxymorphone, hydromorphone, diphenoxylate, morphine sulphate.

\subsection{Prescription non-opioid drugs}

\subsubsection{Central Nervous System (CNS) Depressants}

Used to treat anxiety and sleep disorders. Commonly abused prescription drugs of this category are:

\subsubsection{Clonazepam anddiazepam}

These drugs come under Benzodiazepines. These are prescribed to treat anxiety, seizures and panic disorders. It depresses the CNS, which has a calming effect. Some people misuse it for its fast-acting sedating effects. They produce "highs" and produces the same feeling as that of alcohol.

Other drugs arepentobarbital sodium, alprazolam, zolpidemtartrate and sertraline.

\subsubsection{CNS Stimulants}

Stimulants increases brain activity, boosts alertness and energy levels, used to treat attention deficit hyperactivity disorder (ADHD). Commonly abused prescription drugs of this category are:

Amphetamine

It's a CNS stimulant. It's used to treat attention deficit hyperactivity disorder.

Methylphenidate

Methylphenidate is a stimulant that affects the CNS. It increases dopamine levels in the brain results in improved attention. It is used to treat ADHD and narcolepsy.

Other drugs are dextroamphetamine and Concerta.

\subsubsection{Stages of withdrawal symptoms}

Withdrawal symptoms arises when an addicted person stops to use opioids and non-opioid prescription drugs. This includes:

\section{Early stages}

Symptoms begins around 6 to 30 hours after stopping taking the drug. The timing depends on the type of opiate addiction. During these early stages of withdrawal, the addicted person experiences anxiety, irritability, muscle pain, body aches, tiredness and sweating.

\section{Later stages}

About 72 hours, early symptoms becomes more severe and worst and other symptoms starts appearing which includes drug cravings, anxiety, depression, extreme fatigue, restlessness, muscle and bone pain, insomnia, diarrhoea, vomiting, shivery cold feeling with goose bumps, difficulty in leg movements, panic, excessive sweating, headache, nausea, increased blood pressure/heart rare/breath rate, joint pain, backache, dilated pupils, photophobia, agitation, loss of appetite, abdominal cramps, irritability and eye tearing. 
Overall timeframe

It is observed that the first week of withdrawal is typically worst. After that some symptoms disappears and some lasts longer. These symptoms can lasts up to one month to several months which includes tiredness, depression, anxiety and trouble sleeping.

\subsubsection{Medications used for treatment}

Termination on own from opioid drugs can be very hard and may be dangerous. Medications are available that can help a person get through withdrawal. Treatment most often involves medicines, counselling and support. Medicines must be taken under medical supervision. For instance, some treatments can shorten the withdrawal process and make symptoms less severe. Drugs used for the treatment are listed below with their purpose. (Table 1).

Table 1 Drugs for treatment of opioid and non-opioid withdrawal symptoms

\begin{tabular}{|c|l|l|}
\hline S.No. & \multicolumn{1}{|c|}{ Drugs } & \multicolumn{1}{c|}{ Purpose } \\
\hline 1 & Methadone & $\begin{array}{l}\text { Relieves by reducing the intensity of withdrawal symptoms and helps in abstaining the } \\
\text { body from toxic substances }\end{array}$ \\
\hline 2 & Buprenorphine & $\begin{array}{l}\text { Treats withdrawal symptoms by preventing dependence and misuse and also it can } \\
\text { shorten the length of period of abstaining the body from toxic substances }\end{array}$ \\
\hline 3 & Clonidine & $\begin{array}{l}\text { Used to help reduce anxiety, agitation, muscle aches, sweating, runny nose, hypertension } \\
\text { and cramping }\end{array}$ \\
\hline 4 & Naltrexone & Helps to prevent relapse \\
\hline Some other medications used on basis of symptoms \\
\hline 5 & Loperamide & For diarrhoea \\
\hline 6 & Promethazine & For nausea/vomiting \\
\hline 7 & Ibuprofen & For muscle pain \\
\hline
\end{tabular}

\section{Alcohol addiction $\&$ withdrawal symptoms $[8,9,10,11]$}

Consumption of alcohol is a big problem globally. Consuming alcohol harms mentally, physically and socially. Medical consequences of alcohol abuse includes gastrointestinal complications, cancer, changes in the genitourinary system, muscular changes, neurologicalcomplications, psychiatric complications and other consequences includes suicides and road traffic accidents. Alcohol withdrawal syndrome (AWS) which is cluster of symptoms occurs when people who are dependent on alcohol either stops drinking or reduce the quantity of alcohol intake. AWS ranges from mild to severe. This results from a shift in the neurotransmitter levels in the brain, from GABA inhibition to glutaminergic stimulation. Severe forms of AWS may be associated with generalized seizures, hallucinations and delirium tremens (shaking, confusion and hallucinations), which can be fatal. After 6 hours of alcohol cessation, withdrawal symptoms usually start. According to American academy of family physicians, stages, timeline and symptoms after withdrawal are given below. (Table 2).

Table 2 Stages \& timeline for alcohol withdrawal symptoms

\begin{tabular}{|l|l|l|}
\hline Stages & Timeline & Symptoms \\
\hline Stage 1 & $\begin{array}{l}\text { 6-12 hours after } \\
\text { cessation }\end{array}$ & $\begin{array}{l}\text { Minor hand tremors, sleep disturbances, low-level stress, anxiety, stomach upset, } \\
\text { loss of appetite, sweating and headaches }\end{array}$ \\
\hline Stage 2 & $\begin{array}{l}\text { 12-48 hours after } \\
\text { cessation }\end{array}$ & $\begin{array}{l}\text { Hallucinations, withdrawal seizures, loss of consciousness and violent muscle } \\
\text { contraction }\end{array}$ \\
\hline Stage 3 & $\begin{array}{l}\text { 48-72 hours after } \\
\text { cessation }\end{array}$ & $\begin{array}{l}\text { Delirium tremens, altered mental state, sweating, increased heart rate, blood } \\
\text { pressure \& temperature. }\end{array}$ \\
\hline
\end{tabular}


Central adrenergic storm occurs during alcohol withdrawal results in rapid breathing, tachycardia, hypertension, tremor, hyperthermia and excessive sweating. Low-grade fever occurs due to increased motor activity. Hypothermia occurs with confusion and loss of mental activity.

\subsection{Metabolic and other complications of alcohol withdrawal}

When an addicted person terminates using alcohol, metabolic and other complications may arise. Table below tells the different complications. (Table 3).

Table 3 Complications after alcohol withdrawal

\begin{tabular}{|l|l|}
\hline Complications & Results of complications \\
\hline $\begin{array}{l}\text { Alcoholic ketoacidosis, Electrolyte } \\
\text { disorders }\end{array}$ & $\begin{array}{l}\text { Decreased level of serum magnesium in blood, deficiency of } \\
\text { potassium in blood and elevated concentration of sodium in blood }\end{array}$ \\
\hline Vitamin deficiencies & Vitamin B1, Vitamin K, Vitamin B12, folic acid \\
\hline Cardiac complications & Broken heart syndrome (sudden weakening of heart muscles) \\
\hline Gastrointestinal complications & Inflammation of pancreas \\
\hline Gastrointestinal bleeding & $\begin{array}{l}\text { Peptic ulcer, abnormal and enlarged veins in the lower part of } \\
\text { oesophagus, stomach inflammation }\end{array}$ \\
\hline Hepatic cirrhosis & --- \\
\hline Infectious complications & $\begin{array}{l}\text { Pneumonia, inflammation of brain and spinal cord membranes \& } \\
\text { painful bacterial skin infection }\end{array}$ \\
\hline Neurologic complications & $\begin{array}{l}\text { Wernicke-Korsakoff syndrome due to deficiency of vitamin B1, } \\
\text { loss of neurons and synapses, death of neurons in cerebellum, } \\
\text { bleeding outside the brain due to bursting of blood vessels and } \\
\text { damage of peripheral nerves }\end{array}$ \\
\hline \multicolumn{2}{|c|}{ Delirium tremens usually begins 3 \begin{tabular}{l} 
days after the appearance of withdrawal symptoms \& lasts for 1-8 days. \\
\hline
\end{tabular}}
\end{tabular}

\subsection{Medications used for Treatment}

Summary of medically supervised medication for alcohol withdrawal syndrome are given below. (Table 4).

Table 4 Medications for alcohol withdrawal syndrome

\begin{tabular}{|c|c|}
\hline Drugs & Actions \\
\hline $\begin{array}{l}\text { Benzodiazepines (Diazepam, } \\
\text { Chlordiazepoxide, Lorazepam, } \\
\text { Oxazepam) }\end{array}$ & $\begin{array}{l}\text { Symptom-triggered therapy (anxiety, insomnia and seizures). Diazepam } \\
\text { and Chlordiazepoxide are the mostly used first line drugs in the treatment } \\
\text { of AWS }\end{array}$ \\
\hline $\begin{array}{l}\text { Anti-seizures drugs } \\
\text { (Phenobarbitone) }\end{array}$ & Decrease neurotransmission \\
\hline Beta-blockers (Propranolol) & Decrease blood pressure, pulse rate $\&$ tremor \\
\hline $\begin{array}{l}\text { Acamprosate, Naltrexone, Nalmefene } \\
\text { \& Baclofen }\end{array}$ & Reduces alcohol cravings and feeling of euphoria \\
\hline Disulfiram & $\begin{array}{l}\text { Produces unpleasant effects e.g. flushed face due to filling of more blood in } \\
\text { the blood vessels below the skin, nausea, vomiting, palpitation and } \\
\text { headache when alcohol is taken even in small amount. }\end{array}$ \\
\hline Magnesium & Protects against seizures $\&$ arrhythmias \\
\hline Clonidine & $\begin{array}{l}\text { Reduces central output of adrenergic neurotransmitters \& improves } \\
\text { abnormal vital signs. }\end{array}$ \\
\hline Thiamine & Prevent Wernicke-Korsakoff syndrome \\
\hline Folic acid and Cyanocobalamin & Prevent megaloblastic anaemia \\
\hline
\end{tabular}




\section{Nicotine addiction $\&$ withdrawal symptoms $[12,13,7]$}

\subsection{Tobacco/Nicotine}

Tobacco is a plant in which its leaves are useful. The leaves are collected, dried and fermented before use. Tobacco contains a highly addictive chemical known as nicotine.

\subsection{Symptoms of nicotine withdrawal syndrome}

Nicotine withdrawal symptoms are classified as affective, somatic and cognitive. Affective symptoms include smoking cravings, anxiety/depressed mood/sad, unable to experience pleasure from the enjoyable activities, depression, insomnia, restlessness, high sensitivity to pain and irritability/anger/frustration/bad tempered/upset. Somatic manifestations include tremors, slow heart rate, gastrointestinal discomfort, increased appetite and weight gain. Cognitive symptoms manifest as difficult to concentrate and amnesia. According to The diagnostic and statistical manual of mental disorders reports, the syndrome might also include dizziness, unpleasant dreams, nausea and sore throat. Over time, these symptoms will fade as long as a person stay smoke free.

\subsection{Medications used for treatment}

Medications like Bupropion (antidepressant medication helps to quit smoking) and Varenicline (medication for smoking cessation) are used to treat nicotine withdrawal symptoms. These medicines must be taken under medical supervision. Education, support and counselling are also needed with these medications. Nicotine replacement therapy like gums, patches, inhalers and lozenges are also used which controls the cravings.

\section{Scheme for prohibition and drug abuse prevention in India [14]}

The Government of India financially supports Non-Governmental Organizations (NGOs), de-addiction centers, rehabilitation centers, de-addiction camps, counselling and awareness centers for prohibition and drug abuse prevention. Number of centers according to the available data at present under this Scheme is given in table below. (Table 5).

Table 5 Statistics of centers under scheme for Prohibition and Drug Abuse Prevention

\begin{tabular}{|l|l|l|}
\hline 1 & NGOs running & 361 \\
\hline 2 & Centres for De-addiction and Rehabilitation \& De-addiction Camps & 376 \\
\hline 3 & Centres for counselling and awareness & 68 \\
\hline
\end{tabular}

\section{National drug demand reduction plan}

In our country, drug and substance abuse is a serious problem because the threat of drug abuse in the younger generation has been continuously rising. Drug addiction harms not only the individual's health but also affects addict's families and further the whole society. Regular consumption leads to drug dependence and tolerance. These compounds not only create serious health problems but promote road accidents, suicides and violence including domestic. In consequence, drug abuse must be considered as a psycho-social-medical problem. Keeping these in mind, to make provisions to control and regulate the operations/activities relating to narcotic drugs and psychotropic substances The Narcotic Drugs and Psychotropic Substances (NDPS) Act has enacted in our country in the year 1985.

Since 1985-86, Ministry of social justice and empowerment (MSJE) is working with objectives of identification, motivation, counselling, and de-addiction, rehabilitation of drug dependent persons, training and capacity building of the service providers. MSJE is creating awareness and educating people about the harmful effects of alcohol and substance abuse. According to the report of first national survey on status of drug abuse in India conducted by MSJE with National Drug Dependence Treatment Centre of the All India Institute of Medical Sciences, New Delhi during 2018, the common use of psychoactive substance by Indians are alcohol, cannabis and Opioids in the rank I, II and III respectively. Summary of status of drug abuse in India is given below. (Table 6). 
Table 6 Status of drug abuse in India

\begin{tabular}{|c|l|l|}
\hline S.No. & \multicolumn{1}{|c|}{ Category } & Effected \\
\hline 1 & Individuals use opioids & 2.26 Crore \\
\hline 2 & Estimated individuals need help for their opioid use problems & 77 lakh \\
\hline 3 & Individuals use cannabis products & 3.1 Crore \\
\hline 4 & Suffer from cannabis dependence & 25 lakh \\
\hline 5 & Persons consume alcohol & 16 Crore \\
\hline 6 & Individuals are affected by harmful or dependent alcohol use & $>5.7$ Crore \\
\hline
\end{tabular}

\section{Conclusion}

Addiction of any form affects physically, mentally, financially and socially too. Substances of addiction cause dependence (physical or psychological or both). Once addicted, it is very difficult to get rid of that. If someone alone tries to withdraw from the habit of addiction, withdrawal symptoms arises (physical and mental or both). It is not easy to fight these symptoms; these symptoms can lead to severe health problems and even to death. For this reason, to counter withdrawal symptoms confidence, counselling, emotional help and cooperation and medical support is required and highly recommended. Government of India is taking lot of steps to prohibit and prevent the drug abuse through laws, public awareness through print and electronic media and also recommended schools/college to students through posters, rallies, street plays, debate, speeches, drawing and painting etc. But in school/colleges that much not implemented. Young generation is the future of the country and highly effected from addiction. Now it is the need of hour to talk on this topic and strictly follow the recommendations given by MSJE to spread awareness among youth because spreading awareness is the only way to prevent and to fight against this national problem.

\section{Compliance with ethical standards}

\section{Acknowledgments}

We would like to deliver our sincere thanks to the authors of the articles mentioned in the reference, due to whom we succeeded in writing this article in a better and beneficial way.

\section{Disclosure of conflict of interest}

The authors declare that there is no conflict of interest.

\section{References}

[1] Addiction withdrawal symptoms. Healthdirect Australia.

[2] FDA identifies harm reported from sudden discontinuation of opioid pain medicines and requires label changes to guide prescribers on gradual, individualized tapering. FDA drug safety communication. Available at www.fda.gov/drugs/drug-safety-and-bioavailability/FDA identifies harm reported from sudden discontinuation of opioid pain medicines and requires label changes to guide prescribers on gradual, individualized tapering. Accessed 25 September 2021.

[3] Opiate and opioid withdrawal. MedlinePlus Medical Encyclopedia, National Institutes of Health, U.S.National Library of Medicine.

[4] Shah M, Huecker MR. Opioid Withdrawal. NCBI Bookshelf. A service of the National Library of Medicine, National Institutes of Health.

[5] The Most Commonly Abused Prescription. The recovery village drug and alcohol rehab.

[6] Alan Carter. 9 of the Most Addictive Prescription Drugs on the Market.

[7] Commonly Used Drugs Charts. National institute on drug abuse. 2020. 
[8] Mahato TK, Singh V. Present scenario of policies \& hazards related to alcohol in India, International Journal of Science and Research Archive. 2021; 03(02): 097-106.

[9] Sachdeva A, Choudhary M, Chandra M. Alcohol Withdrawal Syndrome: Benzodiazepines and Beyond. Journal of Clinical and Diagnostic Research. 2015; 9(9): VE01-VE07.

[10] Cooney G, Heydtmann M, Smith ID. Baclofen and the Alcohol Withdrawal Syndrome-A Short Review. Front. Psychiatry. 2019; 9: 773.

[11] Rabindran, Gedam DS. Alcohol Withdrawal Syndrome.

[12] 7 Common Withdrawal Symptoms, Quit Smoking. Tips from Former Smokers.

[13] McLaughlin I, Dani JA, Biasi MD. Nicotine Withdrawal. Curr Top Behav Neurosci. 2015; 24: 99-123.

[14] Mahato TK. Drug Abuse. NDPS Act 1985 \& Drug Demand Reduction: An Update. IOSR Journal of Pharmacy and Biological Sciences. 2020; 15(5): 39-43. 